\title{
A study of Irish consumer's use and perception of nutrition and health claims
}

\author{
A. M. Lynam ${ }^{1,2}$ and A. McKevitt ${ }^{1}$ \\ ${ }^{1}$ School of Biomedical Science, University of Ulster, Coleraine, Co. Derry BT52 1SA, UK and ${ }^{2}$ Department of Clinical \\ Nutrition, St James's Hospital, James's Street, Dublin 8, Republic of Ireland
}

Nutrition and health claims (NHC) made on foods are categorised as nutrition, health or reduction of disease risk claims, according to EU Regulation 1924/2006 ${ }^{(1)}$. Consumer protection and information is the primary remit of this legislation. Research on consumer use of, understanding of and belief in health claims is limited ${ }^{(2,3)}$. The aim of the present study was thus to investigate consumer behaviour in relation to NHC.

An interview-assisted questionnaire was administered to supermarket consumers ( $n$ 400). Consumer preference for five claim types across six products was tested. Perception of claims was assessed across a further eight different food products.

Older $(P<0.001)$ female $(P<0.01)$ participants were more likely to seek NHC. Structure-function and content claims were preferred across six products (Table 1). Consumer interest in NHC was associated with the health benefit claimed rather than the strength of the claim itself (Table 2). Preference for type of claim and perception of claims differed with gender, age and education level.

\begin{tabular}{lcccccc}
\multicolumn{1}{c}{ Table 1. Responses (\%) to the question: 'Which (one) of the following statements best describes the benefits of this product for you?' } \\
\hline & Milk and Ca & $\begin{array}{c}\text { Yoghurt and } \\
\text { probiotics }\end{array}$ & $\begin{array}{c}\text { Spread and } \\
\text { sterols }\end{array}$ & $\begin{array}{c}\text { Juice and } \\
\text { herbs }\end{array}$ & $\begin{array}{c}\text { Cereal and } \\
\text { fibre }\end{array}$ & $\begin{array}{c}\text { Juice and } \\
\text { Soya products }\end{array}$ \\
\hline $\begin{array}{l}\text { Content } \\
\quad \text { ('contains X') }\end{array}$ & 17.8 & 17.3 & 16.5 & 21.5 & 42.0 & 34.0 \\
$\begin{array}{l}\text { Structure-function } \\
\quad \text { ('helps body, because it contains X') }\end{array}$ & 37.8 & 32.5 & 22.3 & 18.5 & 16.8 & 12.5 \\
$\begin{array}{l}\text { Product } \\
\text { ('helps body function') }\end{array}$ & 8.3 & 28.8 & 19.3 & 25.3 & 8.8 & 15.8 \\
$\begin{array}{l}\text { Disease-risk reduction } \\
\text { ('reduces risk of disease, as contains X') }\end{array}$ & 25.8 & 11.3 & 21.8 & 14.0 & 17.5 & 16.5 \\
$\begin{array}{l}\text { Marketing } \\
\text { ('brings benefit, because it contains X') }\end{array}$ & 10.5 & 10.3 & 20.0 & 20.5 & 15.0 & 21.3 \\
\hline
\end{tabular}

Table 2. Consumer opinion (\%) as to whether the following statements are believable, encouraging and understandable

\begin{tabular}{lccc}
\hline Product & Believability & Encouragement & Understandability \\
\hline Spread ('cholesterol-lowering') & 69.3 & 54.3 & 90.5 \\
Probiotic yoghurt ('protects body') & 69.8 & 60.5 & 54.8 \\
Whole-wheat cereal ('enriched') & 85.3 & 45.8 & 90.0 \\
Low-fat milk ('natural and nutritious') & 62.8 & 42.5 & 17.0 \\
Apple fruit drink ('all natural') & 46.8 & 58.0 & 86.5 \\
Milk chocolate ('1.5 glasses of milk') & 58.5 & 13.0 & 87.3 \\
Multivitamin ('for a chaotic lifestyle') & 47.3 & 23.3 & 59.0 \\
Yoghurt ('nourishes skin') & & 54.3 \\
\hline
\end{tabular}

Irish consumers prefer content and simpler health claims, rather than disease-risk reduction claims. This finding is in broad agreement with data from some other European countries. Although reported levels of understanding were high, evidence of positivity bias, and misinterpretation were found. Thus, in relation to EU Regulation 1924/2006 consumers need more information concerning both simpler and more complex claims. Public health messages should be targeted according to gender, age and education level.

1. European Commission (2006) Regulation (EC) No 1924/2006 of the European Parliament and of the Council of 20 December 2006 on nutrition and health claims made on foods. http://eur-lex.europa.eu/LexUriServ/LexUriServ.do?uri=OJ:L:2006:404:0009:0025:EN:PDF

2. van Trijp HCM (2007) Appetite 48, 305-324.

3. Williams P (2005) Nutr Rev 63, 256-264. 